\title{
Composição física da carcaça e características da carne de bovinos de corte terminados em confinamento com diferentes dietas
}

\author{
[Physical composition of carcass and meat characteristics of beef cattle finished in \\ feedlot with different diets] \\ J. Roman ${ }^{1}$, C.C. Jobim ${ }^{1}$, F.D. Resende ${ }^{2}$, G.R. Siqueira ${ }^{2}$, M.H. Faria ${ }^{2}$, R. Rivas $^{3}$ \\ ${ }^{1}$ Universidade Estadual de Maringá - Maringá, PR \\ ${ }^{2}$ Agência Paulista de Tecnologia dos Agronegócios - Pólo Regional da Alta Mogiana - Colina, SP \\ ${ }^{3}$ Centro Universitário da Fundação Educacional de Barretos - Barretos, SP
}

\begin{abstract}
RESUMO
Avaliou-se o efeito de diferentes dietas sobre as características da carcaça e da carne de bovinos de corte em confinamento: dieta composta por silagem de milho e formulação fixa durante o período de confinamento (SMF); dieta composta por silagem de milho e formulação variável durante o período de confinamento (SMV); dieta composta por silagem de cana-de-açúcar e formulação fixa (SCF); dieta composta por silagem de canade-açúcar e formulação variável (SCV); SCV na metade inicial do confinamento e SMV no período final (SCV/SMV). O delineamento experimental foi inteiramente ao acaso, com cinco tratamentos e três repetições. Houve maior deposição de gordura renal-pélvica-inguinal $(\mathrm{P}=0,03)$, de gordura subcutânea $(\mathrm{P}=0,06)$ e de gordura na carcaça $(\mathrm{P}=0,06)$ nas dietas com silagem de milho $(6,7 \mathrm{~kg} ; 6,2 \mathrm{~mm}$ e $34,6 \%)$ em relação àquelas com silagem de cana-de-açúcar (5,3kg; 4,8mm e 31,7\%). Houve maior $(\mathrm{P}=0,05)$ rendimento de contrafilé e de miolo de alcatra nas dietas com silagem de milho (10\% e 6,9\%) em relação às com silagem de cana-de-açúcar (9\% e $6,6 \%)$. Não houve efeito das dietas sobre rendimento de cortes primários $(\mathrm{P}>0,1)$, perdas por cocção $(\mathrm{P}>0,3)$ e força de cisalhamento $(\mathrm{P}>0,1)$. $\mathrm{O}$ ajuste da formulação da dieta e a troca de silagem não influenciaram as características de carcaça e da carne. A utilização de silagem de cana-de-açúcar permitiu carcaças com acabamento satisfatório.
\end{abstract}

Palavras-chave: bovino de corte, espessura de gordura de cobertura, força de cisalhamento, perdas por cocção

\begin{abstract}
The effects of different diets on the carcass and meat characteristics of beef steers in feedlot were evaluated using the following: diet containing corn silage, with fixed formulation during the period of feedlot (CSF); diet containing corn silage, with variable formulation according to the phase of feedlot (CSV); diet containing sugar cane silage with fixed formulation (SCSF); diet containing sugar cane silage, with variable formulation (SCSV); CSV diet in initial half of feedlot and SCSV diet in final half (SCSV/CSV). A completely randomized experimental design with five treatments and three replicates (collective pens) was used. There was higher content of kidney-pelvic-inguinal fat $(P=0.03)$, subcutaneous fat $(P=0.06)$, and fat tissue $(P=0.06)$ deposition in animals fed diets containing corn silage $(6.7 \mathrm{~kg}, 6.2 \mathrm{~mm}$, and $34.6 \%)$ as compared to those fed sugar cane silage $(5.3 \mathrm{~kg}, 4.8 \mathrm{~mm}$, and $31.7 \%)$. A higher $(P=0.05)$ yield of strip loin and rostbiff (\% of hindquarter) were measured in carcasses from animals fed diets containing corn silage (10\% and 6.9\%) than in carcasses from animals fed diets containing sugar cane silage (9\% and 6.6\%). No effects of the diets on yield of primary meat cuts of the carcass $(P>0.1)$, cooking losses $(P>0.3)$, and shear force $(P>0.1)$, with averages of $23.4 \%$ and $4.4 \mathrm{~kg} / \mathrm{m}^{3}$. The adjustment of the diet formulation as the period of confinement and the exchange of silage did not affect the characteristics of carcass and meat. The use of sugar cane silage allowed carcasses with good finishing.
\end{abstract}

Keywords: beef cattle, thickness fat, shear force, cooking losses

Recebido em 17 de novembro de 2009

Aceito em 29 de outubro de 2010

E-mail: julianoroman@yahoo.com.br 


\section{INTRODUÇÃO}

O estudo de estratégias de alimentação que otimizem a produtividade de sistemas de terminação em confinamento é importante para gerar informações que direcionem o manejo alimentar. Isso envolve o estudo de fontes alternativas de alimentos, de manejo da dieta e a resposta animal frente a essas opções. Além disso, a avaliação de seus efeitos sobre as características da carcaça e da carne torna-se cada vez mais relevante face ao aumento das exigências dos consumidores e também como forma de agregar valor econômico ao produto final.

A cana-de-açúcar é amplamente utilizada em sistemas de terminação de bovinos, e, apesar de limitações nutritivas, como baixos teores de proteína bruta e baixa digestibilidade da fibra (Freitas et al., 2006), sua inclusão em dietas balanceadas para bovinos de corte, com correção dessas deficiências, tem mostrado resultados semelhantes à de volumosos de maior qualidade, como a silagem de milho (Vaz e Restle, 2005; Fernandes et al., 2008). Sua utilização tem sido principalmente na forma in natura, mas nos últimos anos tem crescido o interesse pela conservação na forma de silagem, como opção em casos em que há riscos de fogo, de geada, dificuldade logística de colheita diária e do manejo do talhão (Siqueira et al., 2008). No entanto, há ainda limitação de trabalhos que avaliam o efeito da utilização de silagem de cana-de-açúcar em rações para bovinos de corte sobre as características da carcaça.

Este trabalho teve o objetivo de avaliar o efeito da silagem de cana-de-açúcar, em diferentes dietas, em relação à silagem de milho, sobre a composição física da carcaça, o rendimento de cortes e as características da carne de bovinos de corte em confinamento.

\section{MATERIAL E MÉTODOS}

O experimento foi realizado na Estação Experimental da Agência Paulista de Tecnologia dos Agronegócios - Polo Regional Alta Mogiana (APTA Alta Mogiana), localizada em Colina, SP, no período de setembro a dezembro de 2007.

Foram avaliadas cinco dietas para animais em fase de terminação em confinamento: dieta com silagem de milho em sua composição e formulação fixa durante todo o período alimentar (SMF); dieta com silagem de milho em sua composição e formulação variável conforme a fase de confinamento: inicial e final (SMV); dieta com silagem de cana-de-açúcar em sua composição e formulação fixa durante todo o período alimentar (SCF); dieta com silagem de milho em sua composição e formulação variável conforme a fase de confinamento: inicial e final (SCV); dieta com mudança no tipo de volumoso durante o período de alimentação, com fornecimento da dieta SCV no período inicial e SMV no período final (SCV/SMV). O delineamento experimental foi o inteiramente ao acaso, com cinco tratamentos e três repetições (baias coletivas).

O período experimental foi de 96 dias, dividido em período de adaptação dos animais às rações de 14 dias, e dois períodos de 41 dias, que corresponderam às fases de alimentação: inicial e final. Os períodos correspondentes às fases de alimentação foram subdivididos em um período de 20 dias e outro de 21 dias.

As instalações consistiram-se em 15 baias coletivas, sem cobertura, com 240m² (12 x 20m) cada uma. Cada baia comportou 19 animais, disponibilizando para cada animal uma área de $12,6 \mathrm{~m}^{2}$ e $0,63 \mathrm{~m}$ linear de comedouro. Todos os animais tiveram livre acesso à água, disponibilizada em bebedouros nas baias. Foram confinados 285 bovinos castrados, com idade de 36 meses e peso vivo inicial médio de $362,4 \pm 41,6 \mathrm{~kg}$, sendo 230 animais da raça Nelore e 55 cruzados (Zebu x Zebu e Zebu x Holandês). Os animais foram distribuídos nas repetições de acordo com o grupo racial e o peso vivo.

As dietas experimentais (Tab. 1) foram ajustadas pelo modelo Cornell Net Carbohydrate and Protein System (CNCPS) (Sniffen et al., 1992), de modo a serem isoproteicas (14\% PB) e isoenergéticas $(70 \%$ NDT). Consideraram-se estimativas de peso vivo médio dos animais durante todo o período de confinamento (420kg), no caso de tratamentos com dietas fixas, e estimativas de peso vivo médio nas fases inicial (390kg) e final (450kg) do período de alimentação, no caso dos tratamentos com dietas variáveis. A alimentação foi fornecida duas vezes ao dia, pela manhã (8h) e à tarde (16h), permitindo $5 \%$ de sobras. 
Tabela 1. Ingredientes e composição química das dietas experimentais ${ }^{1}$

\begin{tabular}{|c|c|c|c|c|c|c|}
\hline \multirow{3}{*}{ Ingredientes (\%) } & \multicolumn{3}{|c|}{ Silagem de cana-de-açúcar } & \multicolumn{3}{|c|}{ Silagem de milho } \\
\hline & \multirow{2}{*}{$\begin{array}{l}\text { Dieta fixa } \\
\text { (SCF) }\end{array}$} & \multicolumn{2}{|c|}{ Dieta variável (SCV) } & \multirow{2}{*}{$\begin{array}{c}\text { Dieta fixa } \\
\text { (SMF) }\end{array}$} & \multicolumn{2}{|c|}{ Dieta variável (SMV) } \\
\hline & & Inicial & Final & & Inicial & Final \\
\hline Silagem de cana & 35,57 & 34,72 & 37,05 & & & \\
\hline Silagem de milho & & & & 43,76 & 43,17 & 44,10 \\
\hline Farelo de amendoim & 10,19 & 13,62 & 7,00 & 6,32 & 10,42 & 3,17 \\
\hline Polpa cítrica & 35,12 & 35,77 & 34,36 & 34,64 & 33,60 & 35,22 \\
\hline Sorgo, grão moído & 15,32 & 11,95 & 18,03 & 11,54 & 8,96 & 13,86 \\
\hline Fosfato bicálcio & 1,05 & 1,06 & 1,03 & 1,01 & 1,03 & 1,01 \\
\hline Ureia & 1,46 & 1,56 & 1,28 & 1,41 & 1,49 & 1,33 \\
\hline Sulfato de amônio & 0,11 & 0,11 & 0,11 & 0,12 & 0,11 & 0,12 \\
\hline Sal iodado & 0,87 & 0,87 & 0,85 & 0,87 & 0,87 & 0,87 \\
\hline Refinazil $^{\circledR}$ & 0,27 & 0,28 & 0,25 & 0,28 & 0,28 & 0,27 \\
\hline Microminerais, núcleo & 0,02 & 0,02 & 0,02 & 0,02 & 0,02 & 0,02 \\
\hline Monensina sódica & 0,02 & 0,02 & 0,02 & 0,02 & 0,02 & 0,02 \\
\hline \multicolumn{7}{|c|}{ Composição da dieta (\% MS) } \\
\hline Proteína bruta & 14,36 & 15,70 & 12,82 & 14,26 & 15,76 & 12,80 \\
\hline Extrato etéreo & 1,79 & 1,69 & 1,78 & 2,35 & 2,32 & 2,39 \\
\hline Fibra em detergente neutro & 41,77 & 42,98 & 41,46 & 36,70 & 37,30 & 36,10 \\
\hline Nutrientes digestíveis totais & 65,40 & 65,62 & 65,53 & 67,70 & 68,33 & 67,60 \\
\hline Amido & 12,62 & 10,56 & 14,84 & 18,28 & 16,84 & 19,90 \\
\hline
\end{tabular}

${ }^{1}$ SCV/SMV - ração variável inicial de silagem de cana e ração variável final de silagem de milho. NDT: calculado conforme NRC (Nutrient..., 2001). Núcleo de microminerais: - 365g/kg de S, 23890mg/kg de Mn, 76920mg/kg de Z, $23300 \mathrm{mg} / \mathrm{kg}$ de Fe, 23300mg/kg de Cu, 3050mg/kg Co, 2230mg/kg I, 325mg/kg Se.

Após o período experimental, os animais foram abatidos em frigorífico comercial distante $15 \mathrm{~km}$ da Estação Experimental, com jejum de sólidos de 24h. A média de peso ao abate foi de $481,2 \mathrm{~kg}$. $\mathrm{O}$ abate ocorreu em três dias, sendo abatidos 19 animais (baia) de cada tratamento por dia, ou seja, 95 animais. Para avaliação da carcaça, foram amostrados quatro animais de cada repetição (baia), totalizando 60 animais, todos da raça Nelore. A amostragem foi realizada em função do peso vivo em jejum do grupo de animais pertencentes a cada unidade experimental na última pesagem antes do abate.

Após o abate, as carcaças foram identificadas, lavadas, divididas em duas metades e levadas ao resfriamento por $24 \mathrm{~h}$ à temperatura de $-2^{\circ} \mathrm{C}$. A gordura renal - pélvica - inguinal (GRPI) foi coletada na linha de abate e imediatamente pesada. Para avaliação da composição física da carcaça, retirou-se, na meia-carcaça esquerda, a seção da $9^{\mathrm{a}}$ a $11^{\mathrm{a}}$ costelas, conforme metodologia descrita por Hankins e Howe (1946). Após a retirada, a gordura, os ossos e os músculos foram separados e pesados, e os valores obtidos foram utilizados para estimativas das proporções de cada tecido na carcaça por meio das equações desenvolvidas por esses autores, em que a fração músculo é obtida en̂ิ $=16,08+0,80 x$, a fração tecido adiposo (gordura) em $\hat{Y}=3,54+0,80 \mathrm{x}$ e a fração óssea em $\hat{Y}=5,52+0,57 x$.

Retirou-se, ainda, na meia-carcaça esquerda, uma seção do músculo Longissimus dorsi entre a $12^{\mathrm{a}} \mathrm{e}$ $13^{\mathrm{a}}$ costelas da carcaça esquerda para medição da área de olho-de-lombo (AOL) e espessura de gordura subcutânea (EGS), com o auxílio de uma grade quadriculada (Müller, 1987). Nesta seção, retiraram-se amostras (bifes de $2,5 \mathrm{~cm}$ de espessura) para análise de perdas por cocção e força de cisalhamento, as quais foram embaladas a vácuo e congeladas em túnel de congelamento $\left(-30^{\circ} \mathrm{C}\right)$.

As análises de perdas por coç̧ão e força de cisalhamento foram realizadas no Laboratório de Classificação e Análise de Carcaças do Instituto de Zootecnia, localizado em Nova Odessa, SP. No momento das análises, as amostras foram transferidas para uma câmara de resfriamento $\left(2^{\circ} \mathrm{C}\right.$, por $\left.12 \mathrm{~h}\right)$ para descongelamento. As amostras foram assadas em forno pré-aquecido a $170^{\circ} \mathrm{C}$ até atingirem a temperatura interna de aproximadamente $70^{\circ} \mathrm{C}$, momento em que foram retiradas e mantidas em temperatura ambiente para resfriamento (Wheeler et al., 2005). As 
perdas por evaporação foram obtidas pela diferença de peso das bandejas de cozimento com as amostras antes e após o cozimento. O acréscimo de peso das bandejas após o cozimento e sem as amostras representou as perdas por drenagem. As perdas totais resultaram da soma das perdas por drenagem e evaporação.

Nas mesmas amostras em que foram avaliadas as perdas por cocção, foram retiradas seis subamostras cilíndricas (aproximadamente 13mm de diâmetro) do interior de cada amostra, no sentido das fibras musculares, com o auxílio de um vazador manual, para determinação da força de cisalhamento com o aparelho Warner-Bratzler Shear Force (Wheeler et al., 2005).

As meias-carcaças direitas resfriadas foram divididas em dianteiro, ponta-de-agulha e traseiro especial, conforme padrão de cortes comerciais de bovinos estabelecidos pelo MAPA (Ministério..., 1988). A partir do traseiro especial, foram obtidos os cortes comerciais: contrafilé, alcatra, filé-mignon e picanha. Após a separação, cada corte foi pesado individualmente, e procederam-se, então, as aparas desses cortes feitas por profissional treinado do frigorífico onde foi realizado o abate, com obtenção de cortes padrões para exportação: ponta de contrafilé, contrafilé, miolo de alcatra, filé-mignon e picanha. Nos cortes contrafilé, miolo de alcatra e picanha, a espessura da gordura de cobertura foi medida utilizando-se paquímetro.

Os resultados obtidos foram submetidos à análise de variância, e as médias foram comparadas por teste de contrastes ortogonais entre os tipos de silagens (SCF e SCV vs SMF e SMV), entre formulação fixa e variável da dieta dentro de cada

silagem (SCF vs SCV e SMF vs SMV) e entre a dieta em que houve mudança do tipo de silagem (SCV/SMV) e as demais dietas. Realizou-se, ainda, análise de correlação e análise de regressão polinomial entre as variáveis avaliadas. Foi utilizado o pacote estatístico SAS/2001.

\section{RESULTADOS E DISCUSSÃO}

A variação na composição da dieta, seja pelo seu ajuste nutricional ou pela troca de volumoso, não influenciou $(\mathrm{P}>0,26)$ a quantidade de GRPI, a EGS a AOL e a composição física da carcaça dos animais avaliados (Tab. 2).

Tabela 2. Deposição de gordura e composição da carcaça de bovinos de corte alimentados com diferentes rações em confinamento

\begin{tabular}{lcccccc}
\multirow{2}{*}{ Tratamento } & GRPI, & EGS, & \multicolumn{2}{c}{ AOL, } & \multicolumn{2}{c}{ Composição da carcaça (\%) } \\
\cline { 6 - 7 } & $\mathrm{kg}$ & $\mathrm{mm}$ & $\mathrm{cm}^{2} / 100 \mathrm{~kg}$ PV & Osso & Músculo & Gordura \\
\hline SCF (1) & 5,3 & 4,6 & 24,9 & 15,2 & 53,6 & 32,4 \\
SCV (2) & 5,2 & 5,0 & 25,4 & 15,8 & 54,0 & 31,1 \\
SMF (3) & 6,3 & 6,7 & 23,1 & 15,1 & 51,2 & 35,0 \\
SMV (4) & 7,0 & 5,7 & 24,7 & 14,9 & 52,3 & 34,2 \\
SCV/SMV (5) & 6,1 & 5,4 & 24,4 & 15,3 & 54,1 & 31,8 \\
\hline EPM & 0,5 & 0,6 & 0,01 & 0,4 & 1,1 & 1,3 \\
\hline & 0,03 & 0,06 & 0,25 & & & 0,11 \\
\hline e 2 vs 3 e 4 & 0,87 & 0,68 & 0,71 & 0,30 & 0,79 & 0,50 \\
1 vs 2 & 0,40 & 0,29 & 0,27 & 0,65 & 0,49 & 0,68 \\
vs 4 & 0,84 & 0,89 & 0,92 & 0,93 & 0,33 & 0,38 \\
\hline
\end{tabular}

SCF: silagem de cana-de-açúcar e formulação fixa; SCV: silagem de cana-de-açúcar e formulação variável; SMF: silagem de milho e formulação fixa; SMV: silagem de milho e formulação variável; SCV/SMF: dieta SCV na metade inicial e SMV na metade final; GRPI: gordura renal-pélvica-inguinal; EGS: espessura de gordura subcutânea; AOL: área de olho-de-lombo.

Houve efeito, entretanto, do tipo de silagem utilizada, principalmente com relação à deposição de gordura corporal. Rações com silagem de milho proporcionaram maior $(\mathrm{P}=0,03)$ deposição de GRPI, maior $(\mathrm{P}=0,06)$
EGS e maior $(\mathrm{P}=0,06)$ porcentagem de gordura presente na carcaça. Não houve efeito $(\mathrm{P}>0,10)$ do tipo de silagem presente sobre a AOL e porcentagem de tecido ósseo e muscular na 
carcaça, com valores médios de $24,5 \mathrm{~cm}^{2} / 100 \mathrm{~kg}$ $\mathrm{PV}, 15,3 \%$ e $53 \%$, respectivamente.

A maior deposição de gordura na carcaça de animais alimentados com dietas compostas por silagem de milho está relacionada à maior concentração energética verificada nestas dietas em relação às dietas com silagem de cana-deaçúcar (Tab. 1). Vaz e Restle (2005) verificaram maior porcentagem de gordura na carcaça de bovinos da raça Hereford, com idade de 20 meses, quando estes foram alimentados com dietas que continham silagem de milho em relação às com cana-de-açúcar in natura, com valores de $20,6 \%$ e $23 \%$, respectivamente. Brondani et al. (2006) verificaram maior porcentagem de gordura na carcaça de bovinos da raça Charolês, com idade de 36 meses, quando estes foram mantidos em dietas que continham cana-de-açúcar em relação à que usava silagem de milho (15,6\% e 11,9\%, respectivamente), fato atribuído, segundo os autores, à maior permanência dos animais no confinamento para atingir o peso de abate e à maior porcentagem de concentrado na dietas com cana-de-açúcar.

Os valores de porcentagem de gordura relatados por Vaz e Restle (2005) e Brondani et al. (2006) são mais baixos que os encontrados neste experimento, que variou de 31,1 a $35 \%$ e está relacionado às diferenças raciais e à idade dos animais utilizados. Valores próximos à amplitude verificada neste estudo foram relatados por Coan et al. (2008), que, em bovinos da raça Nelore, castrados, com 24 meses de idade, verificaram variação na porcentagem de gordura de 29,9 a $36,1 \%$. Também com animais da raça Nelore, com idade de 20 meses, Vittori et al. (2006) verificaram valores de $27,7 \%$ de gordura na carcaça, e Faturi et al. (2002) valores de 22,4\%.

A cobertura de gordura subcutânea é importante indicador da qualidade final da carne, pois influencia a velocidade de resfriamento da carcaça e interfere na conversão de músculo em carne (Müller, 1987; Felício, 1997). Mesmo havendo menor deposição de gordura em animais alimentados com silagem de cana-de-açúcar, a EGS está acima do limite mínimo (3mm) estabelecido pelos frigoríficos, em que há diminuição da probabilidade de perdas por desidratação e escurecimento da carne durante o resfriamento (Müller, 1987).
A quantificação dos cortes cárneos na carcaça é importante pelos efeitos no valor comercial da carcaça, embora esse fator seja de maior interesse para a indústria frigorífica, sem vantagens econômicas para o produtor rural. Os cortes primários da carcaça de bovinos no mercado brasileiro são o dianteiro com cinco costelas, que compreende o acém e a paleta, o costilhar ou ponta-de-agulha, e o traseiro especial ou serrote, que inclui o coxão e a alcatra completa. Não houve efeito $(\mathrm{P}>0,12)$ das dietas avaliadas sobre o rendimento de cortes primários da carcaça dos animais avaliados, com valores médios de 39,1\% de rendimento de dianteiro, $12,5 \%$ de ponta-de-agulha e $48,4 \%$ de traseiro especial (Tab. 3).

A ausência de efeito do tipo de volumoso no rendimento de cortes comerciais primários também foi verificada por Vaz e Restle (2005), em novilhos da raça Hereford, com valores de $36,8 \%$ de dianteiro, $14,2 \%$ de ponta-de-agulha e $49 \%$ de traseiro especial. Estudos têm demonstrado efeitos sobre a proporção de cortes primários principalmente pelo grupo genético ou composição racial (Faturi et al., 2002; Vittori et al., 2006) e pela condição sexual (Vittori et al., 2006; Fernandes et al., 2008).

A maior agregação de valor na carne bovina ocorre principalmente nos cortes oriundos do traseiro especial, principalmente cortes nobres como a ponta de contrafilé, o contrafilé, o miolo de alcatra, o filé-mignon e a picanha. Dessa forma, o maior rendimento de traseiro, e por sua vez desses principais cortes nobres, resulta em maior valor econômico para as carcaças. Não houve efeito $(\mathrm{P}>0,23)$ do ajuste da dieta ou da troca de silagem sobre o rendimento de cortes nobres, tanto em valores absolutos quanto e, porcentagem do traseiro especial (Tab. 4). Entretanto, houve efeito $(\mathrm{P}=0,05)$ do tipo de silagem sobre o rendimento de contrafilé, de modo que carcaças oriundas de animais alimentados com silagem de milho apresentaram maiores valores em relação àqueles alimentados com silagem de cana-de-açúcar (4,8kg e 10\% vs $4,4 \mathrm{~kg}$ e $9 \%$, respectivamente). Dietas à base de silagem de milho também proporcionaram maior $(\mathrm{P}=0,05)$ rendimento de miolo de alcatra em porcentagem do traseiro. 
Composição física da carcaça...

Tabela 3. Rendimento (\%) de cortes comerciais primários da carcaça de bovinos em confinamento, segundo as dietas alimentares

\begin{tabular}{lccc}
\hline Tratamento & Dianteiro & Ponta-de-agulha & Traseiro especial \\
\hline SCF (1) & 38,2 & 12,6 & 49,2 \\
SCV (2) & 39,5 & 12,3 & 48,2 \\
SMF (3) & 39,2 & 12,6 & 48,2 \\
SMV (4) & 39,1 & 12,8 & 48,1 \\
SCV/SMV (5) & 39,7 & 12,1 & 48,2 \\
\hline EPM & 0,5 & 0,3 & 0,5 \\
\hline & \multicolumn{3}{c}{ Contrastes P>F } \\
1 e 2 vs 3 e 4 & 0,65 & 0,35 & 0,25 \\
3 vs 4 & 0,13 & 0,50 & 0,16 \\
5 vs 1,2,3 e 4 & 0,90 & 0,64 & 0,85 \\
\hline SCF: slagn & 0,23 & 0,71 \\
\hline
\end{tabular}

SCF: silagem de cana-de-açúcar e formulação fixa; SCV: silagem de cana-de-açúcar e formulação variável; SMF: silagem de milho e formulação fixa; SMV: silagem de milho e formulação variável; SCV/SMF: dieta SCV na metade inicial e SMV na metade final.

Tabela 4. Rendimento de cortes nobres da carcaça de bovinos em confinamento, expresso em valores absolutos e porcentagem do traseiro, segundo as dietas alimentares

\begin{tabular}{|c|c|c|c|c|c|c|c|c|c|c|}
\hline \multirow[t]{2}{*}{ Tratamento } & \multicolumn{2}{|c|}{$\begin{array}{l}\text { Ponta de } \\
\text { contrafilé }\end{array}$} & \multicolumn{2}{|c|}{ Contrafilé } & \multicolumn{2}{|c|}{ Miolo de alcatra } & \multicolumn{2}{|c|}{ Filé-mignon } & \multicolumn{2}{|c|}{ Picanha } \\
\hline & $\mathrm{kg}$ & $\%$ & $\mathrm{~kg}$ & $\%$ & $\mathrm{~kg}$ & $\%$ & $\mathrm{~kg}$ & $\%$ & $\mathrm{~kg}$ & $\%$ \\
\hline SCF (1) & 2,0 & 4,0 & 4,6 & 9,4 & 3,2 & 6,6 & 1,7 & 3,4 & 1,4 & 2,9 \\
\hline $\operatorname{SCV}(2)$ & 2,1 & 4,3 & 4,1 & 8,6 & 3,2 & 6,5 & 1,6 & 3,3 & 1,3 & 2,6 \\
\hline SMF (3) & 2,2 & 4,5 & 4,7 & 9,9 & 3,3 & 6,9 & 1,7 & 3,5 & 1,4 & 3,0 \\
\hline SMV (4) & 1,9 & 4,0 & 5,1 & 10,6 & 3,3 & 6,8 & 1,7 & 3,6 & 1,4 & 2,9 \\
\hline SCV/SMV (5) & 1,9 & 4,0 & 4,6 & 9,6 & 3,3 & 6,8 & 1,7 & 3,6 & 1,4 & 2,9 \\
\hline EPM & 0,1 & 0,3 & 0,3 & 0,5 & 0,08 & 0,1 & 0,06 & 0,1 & 0,08 & 0,1 \\
\hline \multicolumn{11}{|c|}{ Contrastes $\mathrm{P}>\mathrm{F}$} \\
\hline 1 e 2 vs 3 e 4 & 0,85 & 0,75 & 0,09 & 0,05 & 0,32 & 0,05 & 0,25 & 0,12 & 0,52 & 0,18 \\
\hline 1 vs 2 & 0,60 & 0,48 & 0,24 & 0,28 & 0,61 & 0,77 & 0,46 & 0,47 & 0,31 & 0,27 \\
\hline 3 vs 4 & 0,29 & 0,32 & 0,40 & 0,35 & 0,44 & 0,55 & 0,60 & 0,47 & 0,61 & 0,84 \\
\hline 5 vs $1,2,3$ e 4 & 0,60 & 0,64 & 0,88 & 0,92 & 0,83 & 0,62 & 0,82 & 0,29 & 0,82 & 0,78 \\
\hline
\end{tabular}

SCF: silagem de cana-de-açúcar e formulação fixa; SCV: silagem de cana-de-açúcar e formulação variável; SMF: silagem de milho e formulação fixa; SMV: silagem de milho e formulação variável; SCV/SMF: dieta SCV na metade inicial e SMV na metade final.

Existem poucos trabalhos na literatura que avaliaram o rendimento de cortes cárneos nobres em função da dieta oferecida, sendo os resultados existentes oriundos de estudos de diferentes grupos genéticos, os quais têm mostrado efeito da composição racial (Bianchini et al., 2007; Bonilha et al., 2007).

Os maiores rendimentos de contrafilé e miolo de alcatra, verificados nas dietas com silagem de milho, podem estar relacionados à maior quantidade de gordura presente na carcaça, visto que a AOL e a quantidade de tecido muscular não foram influenciadas pelas dietas. Houve correlação positiva entre o peso do contrafilé e a espessura da gordura de cobertura $(r=0,71$; $\mathrm{P}=0,003)$ desse corte. Entretanto, não houve diferenças $(\mathrm{P}>0,25)$ entre as dietas avaliadas quanto à espessura da gordura de cobertura do contrafilé (Tab. 5), o que pode ser atribuído ao alto coeficiente de variação verificado (33,8\%). 


\section{Roman et al.}

Tabela 5. Espessura de gordura (mm) de cobertura do contrafilé, miolo de alcatra e de picanha de bovinos em confinamento, segundo as dietas alimentares

\begin{tabular}{lccc}
\hline Tratamento & Contrafilé & Miolo da alcatra & Picanha \\
\hline SCF (1) & 3,9 & 4,2 & 4,7 \\
SCV (2) & 4,0 & 3,7 & 4,3 \\
SMF (3) & 4,7 & 4,9 & 5,4 \\
SMV (4) & 5,3 & 4,2 & 4,5 \\
SCV/SMV (5) & 4,5 & 3,4 & 4,9 \\
\hline EPM & 0,9 & 0,5 & 0,5 \\
\hline \multicolumn{4}{c}{ Contrastes P>F } \\
\hline e 2 vs 3 e 4 & 0,26 & 0,22 & 0,33 \\
1 vs 2 & 0,92 & 0,45 & 0,57 \\
3 vs 4 & 0,62 & 0,35 & 0,20 \\
5 vs 1,2,3 e 4 & 0,97 & 0,16 & 0,70 \\
\hline SCF: silage
\end{tabular}

SCF: silagem de cana-de-açúcar e formulação fixa; SCV: silagem de cana-de-açúcar e formulação variável; SMF: silagem de milho e formulação fixa; SMV: silagem de milho e formulação variável; SCV/SMF: dieta SCV na metade inicial e SMV na metade final.

Também não houve diferença $(\mathrm{P}>0,21)$ na espessura de gordura de cobertura para miolo de alcatra e picanha entre as silagens avaliadas. Diferentemente do contrafilé, o rendimento de miolo de alcatra não se correlacionou $(\mathrm{P}>0,05)$ com a espessura de gordura de cobertura e, dessa forma, outros fatores podem estar envolvidos para determinar maior rendimento nas dietas com silagem de milho, como maior quantidade de gordura intermuscular. Porém, essa variável não foi avaliada. O ajuste da dieta conforme 0 período alimentar e a troca de silagem não influenciaram $(\mathrm{P}>0,16)$ a deposição de gordura de cobertura nos cortes avaliados.
A quantificação das perdas durante a cocção demonstra a capacidade da carne de reter água durante o cozimento, que, por sua vez, é o principal contribuinte para a suculência da carne (Honikel, 2004). Vaz e Restle (2005) relataram correlação positiva entre perdas por cocção e suculência da carne. Não houve efeito $(\mathrm{P}>0,30)$ das dietas avaliadas sobre as perdas totais por cocção do músculo Longissimus dorsi, com valores médios de 23,4\% (Tab. 6). Houve menor $(\mathrm{P}=0,07)$ perda por drenagem na dieta SMF em relação à SMV, mas esse comportamento não foi refletido nas perdas totais.

Tabela 6. Perdas por cocção e força de cisalhamento do músculo L. dorsi de bovinos de corte em confinamento, segundo as dietas alimentares

\begin{tabular}{|c|c|c|c|c|}
\hline Tratamento & $\begin{array}{c}\text { Perdas por evaporação } \\
\text { (\%) }\end{array}$ & $\begin{array}{c}\text { Perdas por } \\
\text { drenagem } \\
(\%) \\
\end{array}$ & $\begin{array}{l}\text { Perdas totais } \\
\text { (\%) }\end{array}$ & $\begin{array}{c}\text { Força de } \\
\text { cisalhamento } \\
\left(\mathrm{kgf} / \mathrm{cm}^{3}\right)\end{array}$ \\
\hline$\overline{\mathrm{SCF}}(1)$ & 14,1 & 9,4 & 23,5 & 4,3 \\
\hline $\operatorname{SCV}(2)$ & 14,6 & 8,6 & 23,2 & 4,4 \\
\hline SMF (3) & 12,3 & 10,0 & 22,3 & 4,1 \\
\hline SMV (4) & 15,2 & 9,5 & 24,7 & 4,7 \\
\hline SCV/SMV (5) & 14,8 & 8,4 & 23,2 & 4,2 \\
\hline EPM & 1,0 & 0,9 & 1,6 & 0,3 \\
\hline \multicolumn{5}{|c|}{ Contrastes $\mathrm{P}>\mathrm{F}$} \\
\hline 1 e $2 v s 3$ e 4 & 0,57 & 0,42 & 0,93 & 0,78 \\
\hline 1 vs 2 & 0,71 & 0,51 & 0,89 & 0,64 \\
\hline 3 vs 4 & 0,07 & 0,68 & 0,31 & 0,15 \\
\hline 5 vs $1,2,3$ e 4 & 0,51 & 0,32 & 0,90 & 0,59 \\
\hline
\end{tabular}

SCF: silagem de cana-de-açúcar e formulação fixa; SCV: silagem de cana-de-açúcar e formulação variável; SMF: silagem de milho e formulação fixa; SMV: silagem de milho e formulação variável; SCV/SMF: dieta SCV na metade inicial e SMV na metade final. 
Em trabalhos que compararam o efeito da inclusão de silagem de milho ou de cana-deaçúcar in natura em dietas para bovinos de corte, não foi verificado efeito do tipo de volumoso sobre as perdas por cocção (Vaz e Restle, 2005; Fernandes et al., 2008). Os valores de perdas de cocção foram próximos aos verificados por Bonilha et al. (2007), em novilhos Nelore abatidos com 22 meses de idade (22,9\%), e por Bianchini et al. (2007), em novilhos Nelore abatidos com 12 meses de idade (23,3\%).

Também não houve efeito $(\mathrm{P}>0,14)$ das dietas avaliadas sobre a força de cisalhamento, com valor médio de $4,4 \mathrm{kgf} / \mathrm{cm}^{3}$. Este valor está abaixo do limite máximo de força de cisalhamento considerada como aceitável, a qual, para a carne bovina, está em torno de $4,6 \mathrm{kgf} / \mathrm{cm}^{3}$ (Shackelford et al., 1991).

A dieta pode interferir na maciez da carne pelo seu valor energético e consequente influência na deposição de gordura intramuscular ou de marmoreio, a qual permite maior facilidade de rompimento dos sarcômeros e das fibras da carne (Di Marco, 1998). Com valores diferentes de deposição de gordura entre volumosos utilizados, poder-se-iam esperar diferenças também nos resultados de força de cisalhamento, entretanto pode não ter havido deposição considerável de gordura intramuscular que promovesse esse efeito, pelo grupo genético utilizado.

Vaz e Restle (2005) não verificaram diferença na força de cisalhamento da carne de novilhos Hereford entre rações que continham silagem de milho ou cana-de-açúcar in natura $\left(7,2 \mathrm{kgf} / \mathrm{cm}^{3}\right)$. Esses autores também não verificaram diferença no marmoreio da carne (7,7 pontos) entre as rações, e relataram correlação positiva entre marmoreio e maciez. Da mesma foram, Fernandes et al. (2008) não verificaram diferença na força de cisalhamento entre rações que continham silagem de milho ou cana-de-açúcar in natura.

\section{CONCLUSÕES}

O ajuste na formulação da dieta conforme o período de confinamento e a troca de silagem de milho por silagem de cana-de-açúcar não influenciam as características de carcaça e da carne de bovinos Nelore terminados em confinamento A utilização de silagem de cana- de-açúcar em rações balanceadas para bovinos de corte permite produção de carcaças com características adequadas de acabamento, com rendimento de cortes, perdas por cocção e maciez semelhantes à silagem de milho.

\section{REFERÊNCIAS BIBLIOGRÁFICAS}

BIANCHINI, W.; SILVEIRA, A.C.; JORGE, A.M. et al. Efeito do grupo genético sobre as características de carcaça e maciez da carne fresca e maturada de bovinos superprecoces. Rev. Bras. Zootec., v.36, supl., p.2109-2117, 2007.

BONILHA, S.F.M.; PACKER, I.U.; FIGUEIREDO, L.A. et al. Efeitos da seleção para peso pós-desmame sobre características de carcaça e rendimento de cortes cárneos comerciais de bovinos. Rev. Bras. Zootec., v.36, p.1275-1281, 2007.

BRONDANI, I.L.; RESTLE, J.; ARBOITTE, M.Z. et al. Efeito de dietas que contêm cana-deaçúcar ou silagem de milho sobre as características de carcaça de novilhos confinados. Cienc. Rural, v.36, p.197-202, 2006.

COAN, R.M.; REIS, R.A.; RESENDE, F.D. et al. Viabilidade econômica, desempenho e características de carcaça de garrotes em confinamento alimentados com dietas contendo silagem de capins tanzânia ou marandu ou silagem de milho. Rev. Bras. Zootec, v.37, p.311318, 2008.

DI MARCO, O.N. Crecimiento y respuesta animal. Balcarce: AAPA, 1998. 246p.

FATURI, C.; RESTLE, J.; BRONDANI, I.L. et al. Características da carcaça e da carne de novilhos de diferentes grupos genéticos alimentados em confinamento com diferentes proporções de grão de aveia e grão de sorgo no concentrado. Rev. Bras. Zootec., v.31, p.20242035, 2002.

FELÍCIO, P.E. Fatores ante e post mortem que influenciam na qualidade da carne bovina. In: PEIXOTO, A.M.; MOURA, J.C.; FARIA, V.P. (Eds). Produção do novilho de corte. Piracicaba: Fundação de Estudos Agrários "Luiz de Queiroz”, 1997. p.79-97. 
FERNANDES, A.R.M.; SAMPAIO, A.A.M.; HENRIQUE, W. et al. Características da carcaça e da carne de bovinos sob diferentes dietas, em confinamento. Arq. Bras. Med. Vet. Zootec., v.60, p.139-147, 2008.

FREITAS, A.W.P.; PEREIRA, J.C.; ROCHA, F.C. et al. Avaliação da divergência nutricional de genótipos de cana-de-açúcar (Saccharum spp.). Rev. Bras. Zootec., v.35, p.229-1236, 2006.

HANKINS, O.G.; HOWE, P.E. Estimation of the composition of beef carcasses and cuts. Washington: US Department of Agriculture, 1946 (Tech. Bull., 926).

HONIKEL, K.O. Water-holding capacity of meat. In: te PAS, M.F.W.; EVERTS, M.E.; HAAGSMAN, H.P. (Eds). Muscle development of livestock animals: physiology, genetics and meat quality. Wallinford: CABI, 2004. 411p.

\section{MINISTÉRIO DA AGRICULTURA, PECUÁRIA E ABASTECIMENTO.}

Padronização dos cortes de carne bovina, 1988. Disponível em:

$<$ http://extranet.agricultura.gov.br/sislegisonsulta/servlet/VisualizarAnexo?id=15075>. Acessado em: 25 set. 2008.

MÜLLER, L. Normas para avaliação de carcaças e concurso de carcaças de novilhos. Santa Maria: UFSM, 1987. 31p.

NUTRIENT requirements of dairy cattle. 7.ed. Washington: National Academy, 2001. 381p.
SHACKELFORD, S.D.; KOOHMARAIE, M.; MILLER, M.F. et al. An evaluation of tenderness of the Longissimus muscle of Angus by Hereford versus Brahman crossbred heifers. J. Anim Sci., v.69, p.171-177, 1991.

SNIFFEN, C.J.; O’CONNOR, J.D.; VAN SOEST, J. et al. A net carbohydrate and protein system for evaluating cattle diets: II. Carbohydrate and protein availability. J. Anim Sci, v.70, p.3562-3577, 1992.

SIQUEIRA, G.R.; RESENDE, F.D.; ROMAN, J. et al. Uso estratégico de forragens conservadas em sistemas de produção de carne. In: JOBIM, C.C.; CECATO, U.; CANTO, M.W. (Eds). Produção e utilização de forragens conservadas. Maringá: Masson, 2008. p.41-88.

VAZ, F.N.; RESTLE, J. Características de carcaça e da carne de novilhos Hereford terminados em confinamento com diferentes fontes de volumoso. Rev. Bras. Zootec., v.34, p.230-238, 2005.

VITTORI, A.; QUEIROZ, A.C.; RESENDE, F.D. et al. Características de carcaça de bovinos de diferentes grupos genéticos, castrados e não castrados, em fase de terminação. Rev. Bras. Zootec., v.35, p.2085-2092, 2006.

WHEELER, T.L.; KOOMARIE, M.; SHALCKELFORD, S.D. Standardized WarnerBratzler shear force procedures for meat tenderness measurement, 2005. Disponível em: <http://www.ars.usda.gov/SP2UserFiles/Place/54 380530/protocols/ ShearForceProcedures.pdf $>$. Acessado em 17 out. 2008. 